\title{
Article \\ Comparison of the Prognostic Value of Ki-67 and Programmed Cell Death Ligand-1 in Patients with Upper Tract Urothelial Carcinoma
}

\author{
Mu-Yao Tsai ${ }^{1}$, Ping-Chia Chiang ${ }^{1}$, Chien-Hsu Chen ${ }^{1,2,3}$, Ming-Tse Sung ${ }^{4}$, Shun-Chen Huang ${ }^{4,5}$, \\ Jau-Ling Suen ${ }^{2,6} \mathbb{D}$, Eing-Mei Tsai ${ }^{2,5,7, *}$ and Po-Hui Chiang ${ }^{1,5, *}$
}

Citation: Tsai, M.-Y.; Chiang, P.-C.; Chen, C.-H.; Sung, M.-T.; Huang, S.-C.; Suen, J.-L.; Tsai, E.-M.; Chiang, P.-H. Comparison of the Prognostic Value of Ki-67 and Programmed Cell Death Ligand-1 in Patients with Upper Tract Urothelial Carcinoma. J. Clin. Med. 2021, 10, 3728. https://doi.org/10.3390/ jcm10163728

Academic Editors: Andreas Skolarikos and Michael Stöckle

Received: 16 July 2021

Accepted: 18 August 2021

Published: 21 August 2021

Publisher's Note: MDPI stays neutral with regard to jurisdictional claims in published maps and institutional affiliations.

Copyright: (c) 2021 by the authors. Licensee MDPI, Basel, Switzerland. This article is an open access article distributed under the terms and conditions of the Creative Commons Attribution (CC BY) license (https:/ / creativecommons.org/licenses/by/ $4.0 /)$.
1 Department of Urology, Kaohsiung Chang Gung Memorial Hospital, Chang Gung University College of Medicine, Kaohsiung 83301, Taiwan; kingtsaiking@gmail.com (M.-Y.T.); pingagaga@hotmail.com (P.-C.C.); kenkochen@yahoo.com.tw (C.-H.C.)

2 Graduate Institute of Medicine, College of Medicine, Kaohsiung Medical University, Kaohsiung 80708, Taiwan; jlsuen@kmu.edu.tw

3 Division of Natural Science, College of Liberal Education, Shu-Te University, Kaohsiung 82445, Taiwan

4 Department of Anatomic Pathology, Kaohsiung Chang Gung Memorial Hospitale, Chang Gung Univerity College of Medicine, Kaohsiung 83301, Taiwan; mtsmts@cgmh.org.tw (M.-T.S.); shuang@cgmh.org.tw (S.-C.H.)

5 College of Medicine, Kaohsiung Medical University, Kaohsiung 80708, Taiwan

6 Research Center for Environmental Medicine, Kaohsiung Medical University, Kaohsiung 80708, Taiwan

7 Department of Obstetrics and Gynecology, Kaohsiung Medical University Hospital, Kaohsiung Medical University, Kaohsiung 80708, Taiwan

* Correspondence: tsaieing@kmu.edu.tw (E.-M.T.); tuoa480713@yahoo.com.tw (P.-H.C.); Tel.: +886-7-3121101 (ext. 6446) (E.-M.T.); +886-7-7317123 (ext. 8094) (P.-H.C.); Fax: +866-7-3112493 (E.-M.T.); +886-7-7354308 (P.-H.C.)

\begin{abstract}
We retrospectively enrolled 102 patients with upper tract urothelial carcinoma (UTUC) who underwent radical nephroureterectomy to examine the prognostic value of Ki-67 and programmed cell death ligand-1 (PD-L1). Then, we performed PD-L1 and Ki-67 immunohistochemical staining on whole tissue sections. The cut-off value of PD-L1 positivity was a combined positive score (CPS) $\geq 10$ and the Ki-67 overexpression was $20 \%$. Among the 102 patients, $16.7 \%$ and $48.0 \%$ showed positive PD-L1 expression and Ki-67 overexpression, respectively. A CPS $\geq 10$ was significantly associated with a higher pathological T stage $(p=0.049)$. In addition, Ki-67 overexpression was significantly associated with a pathological T stage $\geq 2(p=0.027)$ and tumour necrosis $(p=0.016)$. In the multivariable analysis, a positive PD-L1 expression was significantly correlated with worse cancer-specific survival $(\mathrm{HR}=3.66,95 \% \mathrm{CI}=1.37-9.77, p=0.01)$. However, there was no predictive value using a combination of PD-L1 expression and Ki-67 overexpression as a prognostic predictor. Compared with Ki-67 overexpression, a positive PD-L1 expression with CPS $\geq 10$ was a stronger independent prognostic factor for CSS in patients with UTUC.
\end{abstract}

Keywords: combined positive score; Ki-67; programmed cell death ligand-1; radical nephroureterectomy; upper tract urothelial carcinoma

\section{Introduction}

Upper tract urothelial carcinoma (UTUC) accounts for only around 5\% of all urothelial carcinoma (UC) cases [1]. However, in Taiwan, the prevalence of UTUC is unusually high, accounting for more than $10 \%$ of all UC cases; this high prevalence of UTUC may be attributed to the high prevalence of chronic kidney disease [1-5]. In addition, arseniccontaminated well water has been associated with a high prevalence of UC [1,6-8]. Moreover, the prevalence of UTUC was found to be higher in herbalists [9]. Although UTUC has been indicated to have poor prognosis and oncological outcomes, accurate prognostic factors for UTUC are unavailable. Many studies have attempted to develop a prognostic 
model based on postoperative pathological or preoperative parameters; however, novel biomarkers and predictive prognostic models remain under debate $[10,11]$.

Biomarkers may be crucial in predicting a UTUC prognosis. Programmed cell death-1 positivity was found to have an independent prognostic value of cancer-specific survival (CSS) outcomes in patients with UTUC receiving extirpative surgery [12]. Moreover, high-risk clinicopathological factors for UTUC were associated with programmed cell death ligand-1 (PD-L1) positivity [13]. Ki-67, a nuclear cell proliferation marker that can be examined through immunostaining, was frequently found to be expressed in malignant cancers such as breast, colon, and ovarian cancers. A positive Ki-67 expression has been associated with adverse pathological features and poor recurrence- and cancerfree survival in patients with UTUC receiving nephroureterectomy [14-18]. Among the various biomarkers examined previously, Ki-67 appears to be the most potential biomarker with its cell proliferation characteristic $[10,11,19]$. In our previous study, we found that a PD-L1 combined positive score (CPS) $\geq 10$ in UTUC was associated with worse CSS and overall survival (OS) [20]. However, few studies have evaluated the prognostic value of Ki-67 and PD-L1 in combination. In the present study, we investigated the prognostic value of Ki-67 and PD-L1 in UTUC.

\section{Materials and Methods}

\subsection{Study Population}

Between 2013 and 2018, a total of 102 patients with UTUC who underwent radical nephroureterectomy (RNU) through laparoscopic or traditional methods were retrospectively enrolled in this study. We excluded patients without PD-L1 or Ki-67 immunochemical stains, bladder cancer stage $\mathrm{T} 2$ or higher, and patients with distant metastasis at diagnosis or receiving neoadjuvant chemotherapy. Information regarding patients' specimens was obtained from the Surgical Pathology Database of Kaohsiung Chang Gung Memorial Hospital (KCGMH). This study was approved by the Institutional Review Board of KCGMH (Approval No: 202000185B0).

Lymph node staging was performed by radiologists or the treating physician based on the computed tomography (CT) scan findings. Lymph node dissection (LND) was performed during the operation when enlarged lymph nodes were noted. The pathological tumour stage was determined according to the eighth edition of the American Joint Committee on Cancer's staging system for cancer of the renal pelvis and ureter.

Locoregional recurrence was defined as the presence of a recurrent lesion at the previous operation site or the evidence of retroperitoneal lymph node enlargement on the CT scan during follow-up. Distant metastasis was defined as the evidence of suspicious lesions on radiological images. In addition, recurrent bladder cancer was determined on the basis of pathological reports. The history of bladder cancer and the cause of death were determined through a chart review.

\subsection{Immunohistochemistry}

Specimen staining was performed by a specialised pathologist (SMZ). The tissue samples submitted for the PD-L1 study were fixed in formalin, embedded in paraffin, and sectioned into 3- $\mu \mathrm{m}$ thickness. The immunohistochemical examination of PD-L1 was performed using a Dako anti-PD-L1 (clone 22C3) mouse monoclonal primary antibody purchased from Agilent Technologies (Santa Clara, CA, USA). The detection system used was the EnVision FLEX Visualisation System (Dako North America, Inc., Carpinteria, CA, USA). Immunostaining was performed using a Dako Autostainer Link 48 (Dako North America, Inc., Carpinteria, CA, USA). Figure 1 shows a representative picture of positive and negative PD-L1 expressions observed through immunohistochemical staining. 

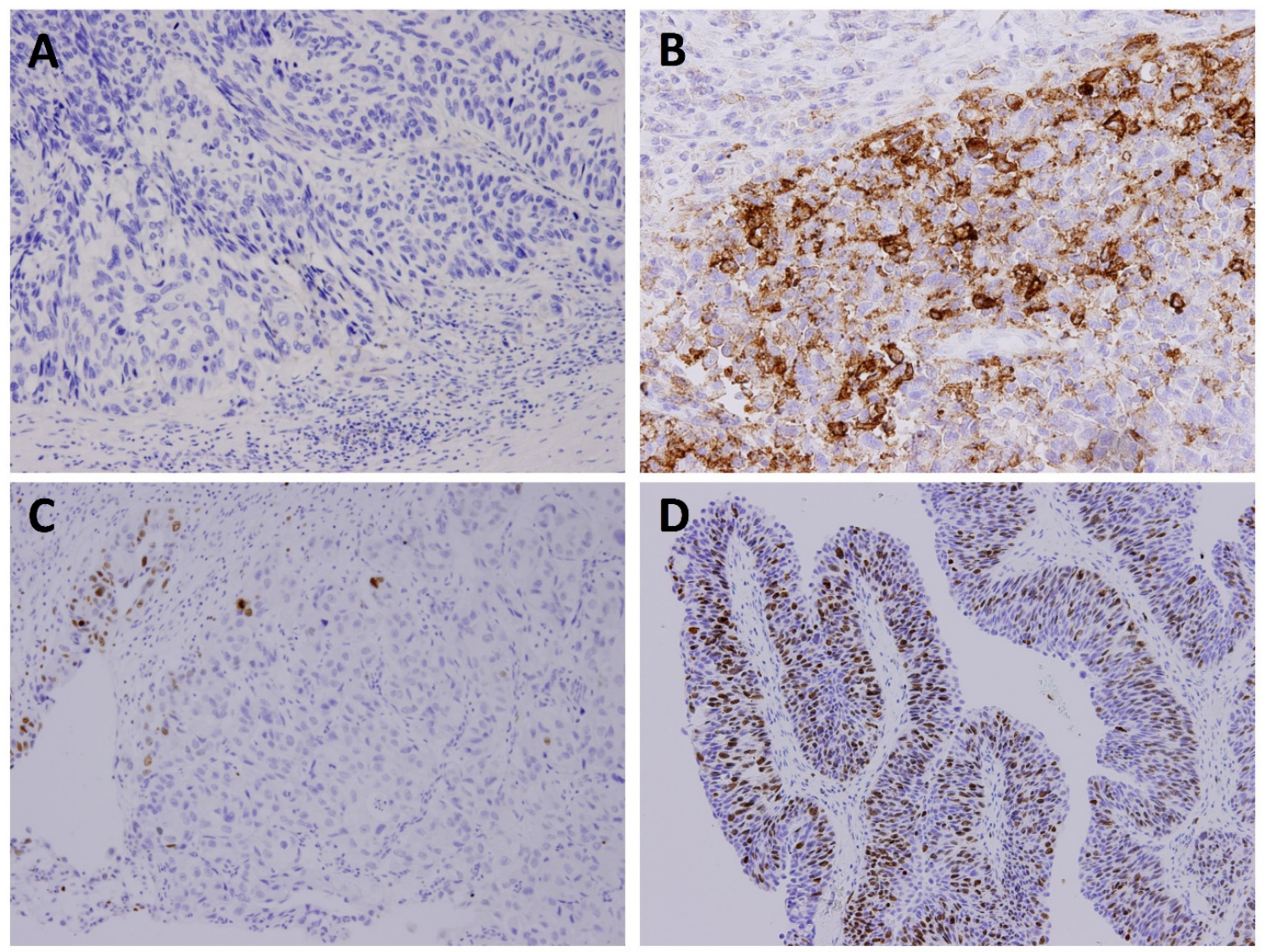

Figure 1. Representative photomicrographs showing PD-L1 expression through immunostaining (200×): (A) Negative PD-L1 expression (CPS < 10) and (B) PD-L1 expression (CPS = 50). Representative photomicrographs showing Ki-67 expression: (C) $5 \%$ and (D) $70 \%$.

The specimens for Ki-67 immunostaining were fixed in 10\% formalin, embedded in paraffin, and sectioned into 1- $\mu \mathrm{m}$ thickness. The tissue sections were deparaffinised using xylene and a graded ethanol series and then heated in boiling 0.01-M citrate buffer ( $\mathrm{pH}$ 6.0) for $15 \mathrm{~min}$ in a microwave oven for antigen retrieval. Subsequently, the sections were incubated with the primary mouse monoclonal anti-Ki-67 antibody (clone MIB-1; Dako, Glostrup, Denmark) diluted in the antibody diluent reagent solution (ScyTek, Logan, UT, USA) at room temperature for $60 \mathrm{~min}$, rinsed with a buffer, amplified using the Quanto Amplifier and Quanto HRP polymer (Thermo Scientific, Kalamazoo, MI, USA), labelled with DAB chromogen (Bio SB, Santa Barbara, CA, USA), and then counterstained with haematoxylin. A negative reagent control was set, in which the patient tissue was processed using the same steps, except for incubation with the primary antibody. A small section of the tonsil tissue attached on each experimental slide was used as the positive (germinal centre) and negative (mature squamous epithelium) tissue control.

\subsection{Immunohistochemical Analysis}

The combined positive score (CPS) was used to examine the PD-L1 expression in the tissue sections. The CPS was defined as the ratio of the number of PD-L1-stained cells (tumour cells, lymphocytes, and macrophages) to the total number of tumour cells. We performed a time-dependent receiver operating characteristic (ROC) curve and survival ROC curve by the SAS system to find the cut-off value of PD-L1 in this study. A CPS $\geq 10$ was found to be the optimal cut-off value of this study CPS of $<10$ and $\geq 10$ indicated negative and positive PD-L1 expressions, respectively (Figure 1).

We visually calculated the Ki-67 index by counting the total number of stained tumour cells and the total number of tumour cells in each high-power field for a total of five 
high-power fields. The Ki-67 index was calculated as the number of stained tumour cells divided by the total number of tumour cells and then multiplied by 100 . The cut-off value of Ki-67 overexpression was also calculated by the SAS system by the same methods. Ki-67 overexpression was considered when the samples exhibited a nuclear reactivity of $\geq 20 \%$ (Figure 1).

\subsection{Statistical Analysis}

The relationships among the PD-L1 expression, Ki-67 overexpression, clinical characteristics, and pathological features were examined using the chi-square test or Fisher's exact test. The Kaplan-Meier method was used to evaluate the survival function, and the differences were examined using the log-rank test. Univariable and multivariable Cox proportional hazard regression models by forward stepwise selection for the OS, as well as CSS, were used to assess the prognostic indicators-namely, sex, age at diagnosis, PD-L1 expression, Ki-67 overexpression, tumour node metastasis classification, and other clinicopathological characteristics. The level of significance was set at $p<0.05$. All statistical analyses were performed using SPSS (IBM Corp. Released 2011. IBM SPSS Statistics for Windows, Version 20.0. Armonk, NY: IBM Corp. USA).

\section{Results}

\subsection{Patient Characteristics}

Table 1 lists the patients' demographic characteristics. The median age of all 102 patients was 69 years, and 62 patients were aged $>65$ years. Of the 102 patients, $51(50.0 \%)$ were men and 51 (50.0\%) were women; moreover, 40 (39.2\%) were diagnosed as having pathological T3 or higher UTUC, and 14 (13.7\%) exhibited lymph nodes of $>10 \mathrm{~mm}$ in size on their CT findings at diagnosis. In addition, six (5.9\%), eight (7.8\%), and eight (7.8\%) patients received palliative immunotherapy (pembrolizumab was the main regimen), adjuvant chemotherapy, and palliative chemotherapy, respectively.

Table 1. Demographic characteristics of the 102 patients with UTUC.

\begin{tabular}{ll}
\hline Variables & $N(\mathbf{\%})$ \\
\hline Age $>65$ years & $62(60.8)$ \\
Gender & $51(50.0)$ \\
Male & $51(50.0)$ \\
Female & \\
Lymph node $>10$ mm on CT at diagnosis & $88(86.3)$ \\
Absent & $14(13.7)$ \\
Present & \\
Pathologic stage & $25(24.5)$ \\
pTa/is & $16(15.7)$ \\
pT1 & $21(20.6)$ \\
pT2 & $32(31.4)$ \\
pT3 & $8(7.8)$ \\
pT4 & $8(7.8)$ \\
Adjuvant chemotherapy & $6(5.9)$ \\
Palliative immunotherapy & $8(7.8)$ \\
Palliative chemotherapy & $17(16.7)$ \\
PD-L1 CPS $\geq 10$ & $49(48.0)$ \\
Ki-67 $\geq 20$ &
\end{tabular}

\subsection{Association of PD-L1 Expression and Ki-67 Overexpression with Clinicopathological Characteristics}

Of the 102 patients, 18 and 49 exhibited positive PD-L1 expression and Ki-67 overexpression, respectively. The results are presented in Table 2. The follow-up duration was significantly shorter in patients with a CPS of $\geq 10$ (19.8 \pm 20.5 vs. $37.2 \pm 24.0$ months, $p=0.006)$ and those with a Ki-67 index of $\geq 20(28.4 \pm 20.9$ vs. $39.9 \pm 25.9$ months, $p=0.016)$. 
Table 2. The association of PD-L1 expression and Ki-67 expression with the clinicopathological characteristics in patients with UTUC.

\begin{tabular}{|c|c|c|c|c|c|c|}
\hline & PD-L1 CPS $\geq 10$ & PD-L1 CPS < 10 & $p$-Value & Ki-67 $\geq 20$ & Ki-67 $<20$ & $p$-Value \\
\hline & $N(\%)$ & $N(\%)$ & & $N(\%)$ & $N(\%)$ & \\
\hline Patient number & $17(16.7)$ & $85(83.3)$ & & $49(48.0)$ & $53(52.0)$ & \\
\hline Follow duration & $19.8 \pm 20.5(\mathrm{mo})$ & $37.2 \pm 24.0(\mathrm{mo})$ & $0.006^{*}$ & $28.4 \pm 20.9(\mathrm{mo})$ & $39.9 \pm 25.9(\mathrm{mo})$ & 0.016 * \\
\hline Age & & & 0.468 & & & 0.192 \\
\hline$>65 \mathrm{yr}$ & $9(52.9)$ & $53(62.4)$ & & $33(67.3)$ & $29(54.7)$ & \\
\hline$\leq 65 \mathrm{yr}$ & $8(47.1)$ & $32(37.6)$ & & $16(32.7)$ & $24(45.3)$ & \\
\hline Gender & & & 0.184 & & & 1.000 \\
\hline Male & $11(64.7)$ & $40(47.1)$ & & $24(49.0)$ & 27 (50.9) & \\
\hline Female & $6(35.3)$ & 45 (52.9) & & $25(51.0)$ & $26(49.1)$ & \\
\hline Pathologic stage & & & $0.049 *$ & & & 0.160 \\
\hline $\mathrm{pTa} /$ is & $0(0)$ & $25(29.4)$ & & 7 (14.3) & $18(34.0)$ & \\
\hline pT1 & $3(17.6)$ & $13(15.3)$ & & 7 (14.3) & $9(17.0)$ & \\
\hline pT2 & $5(29.4)$ & $16(18.8)$ & & $12(24.4)$ & $9(17.0)$ & \\
\hline pT3 & $7(41.2)$ & $25(29.4)$ & & 19 (38.8) & $13(24.5)$ & \\
\hline pT4 & $2(11.8)$ & $6(7.1)$ & & $4(8.2)$ & $4(7.5)$ & \\
\hline Muscle-invasive tumour & & & 0.056 & & & $0.027^{*}$ \\
\hline $\begin{array}{l}<\mathrm{T} 2 \\
>\mathrm{T} 2\end{array}$ & $3(17.6)$ & $38(44.7)$ & & $14(28.6)$ & $27(50.9)$ & \\
\hline Lymph node status & $14(82.4)$ & 47 (55.3) & & 35 (71.4) & $26(49.1)$ & \\
\hline N0/Nx & $12(70.6)$ & $76(89.4)$ & 0.055 & $44(89.8)$ & $44(83.0)$ & 0.395 \\
\hline $\mathrm{N} 1 / \mathrm{N} 2$ & $5(29.4)$ & $9(10.6)$ & & $5(10.2)$ & $9(17.0)$ & \\
\hline Papillary feature & & & 0.142 & & & 0.133 \\
\hline Absent & $8(47.1)$ & $22(25.9)$ & & $18(36.7)$ & $12(22.6)$ & \\
\hline Present & $9(52.9)$ & $63(74.1)$ & & $31(63.3)$ & $41(77.4)$ & \\
\hline Tumour grade & & & 0.255 & & & 0.054 \\
\hline Low & $0(0)$ & $11(12.9)$ & & $2(4.1)$ & $9(17.0)$ & \\
\hline High & $17(100)$ & $74(87.1)$ & & $47(95.9)$ & $44(83.0)$ & \\
\hline Lymphovascular invasion & & & 0.156 & & & 0.093 \\
\hline Absent & $9(52.9)$ & 60 (70.6) & & $29(59.2)$ & $40(75.5)$ & \\
\hline Present & $8(47.1)$ & $25(29.4)$ & & $20(40.8)$ & $13(24.5)$ & \\
\hline Concomitant CIS & & & 1.000 & & & 0.690 \\
\hline Absent & $7(41.2)$ & $35(41.2)$ & & $19(38.8)$ & $23(43.4)$ & \\
\hline Present & $10(58.8)$ & $50(58.8)$ & & $30(61.2)$ & $30(56.6)$ & \\
\hline Squamous differentiation & & & 0.363 & & & 0.825 \\
\hline Absent & $11(61.1)$ & 65 (76.5) & & 36 (73.5) & $40(75.5)$ & \\
\hline Present & $6(38.9)$ & $20(23.5)$ & & $13(26.5)$ & $13(24.5)$ & \\
\hline Margin positive & & & 1.000 & & & 1.000 \\
\hline Negative & $15(88.2)$ & 75 (88.2) & & $43(87.8)$ & 47 (88.7) & \\
\hline Positive & $2(11.8)$ & $10(11.8)$ & & $6(12.2)$ & $6(11.3)$ & \\
\hline Tumour necrosis & & & 0.179 & & & $0.016 *$ \\
\hline Absent & $7(41.2)$ & $52(61.2)$ & & $22(44.9)$ & $37(69.8)$ & \\
\hline Present & $10(58.8)$ & $33(38.8)$ & & $27(45.1)$ & $16(30.2)$ & \\
\hline Multifocal tumour & & & 0.772 & & & 0.521 \\
\hline Solitary & $13(76.5)$ & $59(69.4)$ & & $33(67.3)$ & 39 (73.6) & \\
\hline Multifocal & $4(23.5)$ & $26(30.6)$ & & $16(32.7)$ & $14(26.4)$ & \\
\hline Bladder recurrence & & & 0.010 * & & & 0.495 \\
\hline Yes & $0(0)$ & $24(28.2)$ & & $10(20.4)$ & $14(26.4)$ & \\
\hline No & 17 (100) & $61(71.8)$ & & 39 (79.6) & 39 (73.6) & \\
\hline Locoregional recurrence & & & 0.222 & & & 0.641 \\
\hline Yes & $6(38.9)$ & $18(21.2)$ & & $13(26.5)$ & $11(20.8)$ & \\
\hline No & $11(61.1)$ & $67(78.8)$ & & $36(73.5)$ & $42(79.2)$ & \\
\hline Distant metastasis & & & 0.518 & & & 1.000 \\
\hline Yes & $5(29.4)$ & $17(18.8)$ & & $11(22.4)$ & $11(20.8)$ & \\
\hline No & $12(70.6)$ & $68(81.2)$ & & 38 (77.6) & $42(79.2)$ & \\
\hline Adjuvant chemotherapy & & & 1.000 & & & 1.000 \\
\hline Yes & $1(5.9)$ & $7(8.2)$ & & $4(8.2)$ & $4(7.5)$ & \\
\hline No & $16(94.1)$ & $78(91.8)$ & & $45(71.8)$ & 49 (92.5) & \\
\hline Palliative chemotherapy & & & 0.617 & & & 1.000 \\
\hline Yes & $2(11.8)$ & $6(7.1)$ & & $4(8.2)$ & $4(7.5)$ & \\
\hline No & $15(88.2)$ & $79(92.9)$ & & $45(71.8)$ & $49(92.5)$ & \\
\hline $\begin{array}{c}\text { Palliative } \\
\text { immunotherapy }\end{array}$ & & & $0.007^{*}$ & & & 0.102 \\
\hline Yes & $4(23.5)$ & $2(2.4)$ & & $5(10.2)$ & $1(1.9)$ & \\
\hline No & $13(76.5)$ & $83(97.6)$ & & $44(89.8)$ & $52(98.1)$ & \\
\hline Death due to UTUC & & & 0.067 & & & 0.661 \\
\hline Yes & $8(47.1)$ & $19(22.4)$ & & $14(28.6)$ & $13(24.5)$ & \\
\hline No & $9(52.9)$ & 66 (77.6) & & $35(71.4)$ & 40 (75.5) & \\
\hline
\end{tabular}


A PD-L1-positive expression was associated with a higher T stage $(p=0.049)$, higher proportion of patients receiving palliative immunotherapy $(23.5 \%$ vs. $2.4 \%, p=0.007)$, and lower proportion of patients exhibiting bladder tumour recurrence after an operation during follow-up ( $0 \%$ vs. $28.2 \%, p=0.01)$. A higher proportion of patients with a pathological T stage $\geq 2$ showed Ki-67 overexpression ( $71.4 \%$ vs. $49 \%, p=0.027)$. Furthermore, the patients with $\mathrm{Ki}-67$ overexpression showed a higher proportion of tumour necrosis in specimens $(45.1 \%$ vs. $30.2 \%, p=0.016)$.

\subsection{Association of Evaluated Predictors and Survival Outcomes \\ 3.3.1. Kaplan-Meier Analysis}

The Kaplan-Meier analysis results showed that a positive PD-L1 expression was associated with a shorter CSS $(p<0.002$; Figure 2$)$. A Ki-67 overexpression was not associated with the OS ( $p=0.082)$ or CSS ( $p=0.368$; Figure 2).
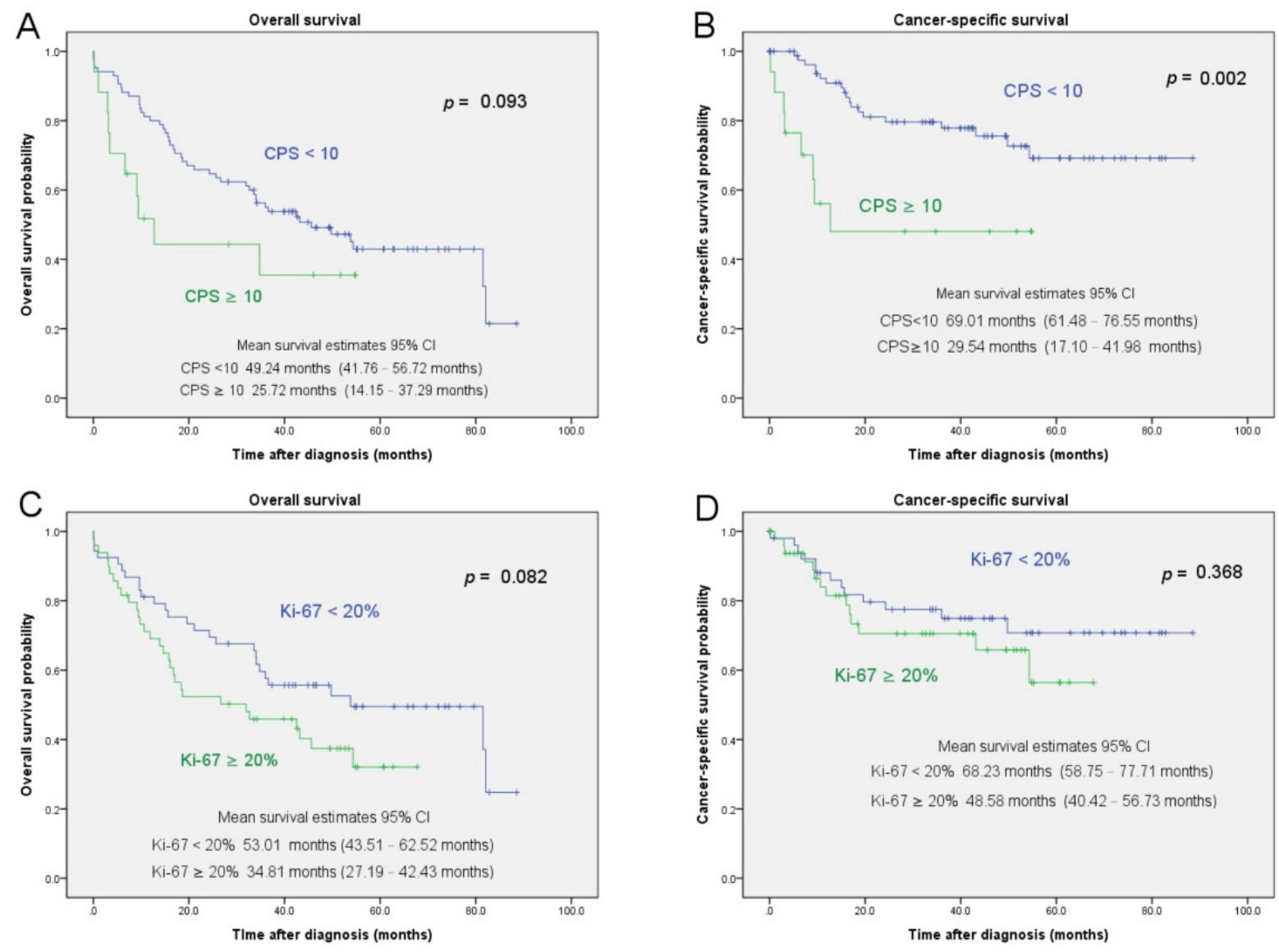

Figure 2. The OS and CSS estimates after RNU for patients with UTUC based on PD-L1 expression and Ki-67 overexpression. Subfigure (A,B) showed probability of OS and CSS after RNU stratified according to PD-L1 expression, respectively. Subfigure (C,D) showed probability of OS and CSS after RNU stratified according to Ki-67 expression, respectively.

\subsubsection{Multivariable Analysis for OS and CSS}

In the multivariable analysis using forward stepwise selection for the OS (Table 3), age over 65 years $(\mathrm{HR}=2.96,95 \% \mathrm{CI}=1.55-5.65, p<0.001)$ and a higher $\mathrm{T}$ stage were also found to be independent risk factors for a shorter OS. In addition, a positive PD-L1 expression did not show a significant correlation with the OS, and the combination of CPS $\geq 10$ and Ki-67 $\geq 20 \%$ did not show significance. Furthermore, a positive PD-L1 expression $(\mathrm{HR}=3.66,95 \% \mathrm{CI}=1.37-9.77, p=0.01)$, a lymph node $\geq 10 \mathrm{~mm}$ in size on a CT scan $(\mathrm{HR}=5.06,95 \% \mathrm{CI}=1.97-13.02, p=0.001)$, receiving palliative chemotherapy $(\mathrm{HR}=2.80,95 \% \mathrm{CI}=1.02-7.64, p=0.045)$, and a higher $\mathrm{T}$ stage were independent risk 
factors for shorter CSS. The combination of positive PD-L1 and overexpression of Ki-67 was not correlated with CSS after the analysis.

Table 3. Univariable and multivariable analyses by the forward stepwise selection of the clinicopathological features for the prediction of CSS and OS in patients with UTUC.

\begin{tabular}{|c|c|c|c|c|c|c|c|c|}
\hline & \multicolumn{4}{|c|}{ Cancer-Specific Survival } & \multicolumn{4}{|c|}{ Overall Survival } \\
\hline & \multicolumn{2}{|c|}{ Univariable } & \multicolumn{2}{|c|}{ Multivariable * } & \multicolumn{2}{|c|}{ Univariable } & \multicolumn{2}{|c|}{ Multivariable * } \\
\hline & HR (95\% CI) & $p$-Value & HR (95\% CI) & $p$-Value & HR $(95 \%$ CI) & $p$-Value & HR $(95 \%$ CI) & $p$-Value \\
\hline Age (year) & & & & & & & & \\
\hline$>65$ vs. $\leq 65$ & $\begin{array}{c}2.18 \\
(0.95-5.03)\end{array}$ & 0.067 & & & $\begin{array}{c}3.14 \\
(1.68-5.88)\end{array}$ & $<0.001$ & $\begin{array}{c}2.96 \\
(1.55-5.65)\end{array}$ & $<0.001$ * \\
\hline $\begin{array}{c}\text { PD-L1 expression } \\
\text { CPS } \geq 10 \text { vs. }<10 \\
\text { Ki-67 } \\
\text { overexpression }\end{array}$ & $\begin{array}{c}3.46 \\
(1.51-7.96)\end{array}$ & 0.003 & $\begin{array}{c}3.66 \\
(1.37-9.77)\end{array}$ & $0.01 *$ & $\begin{array}{c}1.79 \\
(0.90-3.57)\end{array}$ & 0.098 & & \\
\hline$\geq 20 \%$ vs. $<20 \%$ & $\begin{array}{c}1.41 \\
(0.66-3.01)\end{array}$ & 0.371 & & & $\begin{array}{c}1.60 \\
(0.94-2.72)\end{array}$ & 0.085 & & \\
\hline \multicolumn{9}{|l|}{$\begin{array}{l}\text { PDL1 and Ki-67 } \\
\text { expression }\end{array}$} \\
\hline $\begin{array}{c}\text { Both positive vs. } \\
\text { negative }\end{array}$ & $\begin{array}{c}3.90 \\
(1.46-10.40)\end{array}$ & 0.006 & & & $\begin{array}{c}2.07 \\
(0.88-4.87)\end{array}$ & 0.094 & & \\
\hline $\begin{array}{c}\text { Ts stage } \\
\mathrm{Ta} / \text { is }\end{array}$ & Referent & $<0.001$ & Referent & $0.021 *$ & Referent & 0.001 & Referent & $0.001 *$ \\
\hline $\mathrm{T} 1$ & $\begin{array}{c}1.64 \\
(0.23-11.63)\end{array}$ & 0.622 & $\begin{array}{c}0.86 \\
(0.12-6.36)\end{array}$ & 0.881 & $\begin{array}{c}1.85 \\
(0.68-5.02)\end{array}$ & 0.226 & $\begin{array}{c}1.61 \\
(0.59-4.36)\end{array}$ & 0.354 \\
\hline $\mathrm{T} 2$ & $\begin{array}{c}3.18 \\
(0.58-17.42)\end{array}$ & 0.183 & $\begin{array}{c}1.82 \\
(0.30-11.07)\end{array}$ & 0.515 & $\begin{array}{c}2.44 \\
(0.99-5.99)\end{array}$ & 0.053 & $\begin{array}{c}2.28 \\
(0.93-5.61)\end{array}$ & 0.072 \\
\hline $\mathrm{T} 3$ & $\begin{array}{c}6.97 \\
(1.52-32.02)\end{array}$ & 0.013 & $\begin{array}{c}3.22 \\
(0.65-15.98)\end{array}$ & 0.152 & $\begin{array}{c}3.76 \\
(1.62-8.77)\end{array}$ & 0.002 & $\begin{array}{c}2.79 \\
(1.18-6.57)\end{array}$ & $0.019 *$ \\
\hline $\mathrm{T} 4$ & $\begin{array}{c}27.42 \\
(5.70-131.87)\end{array}$ & $<0.001$ & $\begin{array}{c}8.96 \\
(1.62-49.51)\end{array}$ & $0.012 *$ & $\begin{array}{c}8.10 \\
(2.94-22.30)\end{array}$ & $<0.001$ & $\begin{array}{c}8.30 \\
(2.98-23.12)\end{array}$ & $<0.001$ * \\
\hline $\begin{array}{l}\text { Lymph node status } \\
\text { N1/N2 vs. N0/Nx }\end{array}$ & $\begin{array}{c}6.84 \\
(3.07-15.25)\end{array}$ & $<0.001$ & $\begin{array}{c}5.06 \\
(1.97-13.02)\end{array}$ & $0.001 *$ & $\begin{array}{c}2.90 \\
(1.48-5.69)\end{array}$ & 0.002 & & \\
\hline $\begin{array}{c}\text { Adjuvant } \\
\text { chemotherapy }\end{array}$ & & & & & & & & \\
\hline Yes vs. No & $\begin{array}{c}3.08 \\
(1.14-8.30)\end{array}$ & 0.026 & & & $\begin{array}{c}1.79 \\
(0.76-4.23)\end{array}$ & 0.182 & & \\
\hline $\begin{array}{c}\text { Palliative } \\
\text { chemotherapy }\end{array}$ & & & & & & & & \\
\hline Yes vs. No & $\begin{array}{c}4.53 \\
(1.91-10.74)\end{array}$ & 0.001 & $\begin{array}{c}2.80 \\
(1.02-7.64)\end{array}$ & $0.045^{*}$ & $\begin{array}{c}1.96 \\
(0.89-4.34)\end{array}$ & 0.097 & & \\
\hline $\begin{array}{c}\text { Palliative } \\
\text { immunotherapy }\end{array}$ & & & & & & & & \\
\hline Yes vs. No & $\begin{array}{c}3.21 \\
(0.95-10.86)\end{array}$ & 0.061 & & & $\begin{array}{c}1.50 \\
(0.47-4.86)\end{array}$ & 0.495 & & \\
\hline
\end{tabular}

* Variables significant in the univariable analysis were included to perform the multivariable analysis by forward stepwise selection.

\section{Discussion}

According to the 2020 European Association of Urology (EAU) guidelines, several factors are associated with a poor prognosis of UTUC, including a high pathological stage, older age, multifocality, and hydronephrosis [21]. These guidelines were based on the findings of some studies examining the prognostic value of biomarkers intraoperatively and postoperatively. In a study conducted by Skala et al., they reported that PD-L1 positivity was associated with a high histological grade, a high pathological stage, and angiolymphatic invasion [13]. Another study conducted in 2017 reported that PD-L1 expression in UTUC cells independently predicted a shorter CSS [22]. Miyama et al. performed a retrospective study by recruiting 271 patients with UTUC who underwent nephroureterectomy and found that a high platelet count and PD-L1 positivity were significantly associated with a shorter metastasis-free survival [23]. However, most of these studies did not find an association between PD-L1 positivity and CSS or OS. Moreover, the aforementioned studies were limited by their small sample sizes and retrospective design. In this study, we defined PD-L1 positivity by CPS (a combination of tumour cells and immune cells). Several studies found that it was more helpful to incorporate 
tumour-associated immune cells into the positivity of PD-L1 to select responders than using tumour cells alone [24,25]. Besides, it is easily and repeatable to calculate the tumour cells and immune cells at the same time. Therefore, CPS may be a feasible and better way to predict the prognosis.

A prospective study was conducted by Krabbe, L.M. et al. to investigate the prognostic value of Ki-67 in patients with UTUC who underwent RNU [14]. This study indicated an association between Ki-67 overexpression and adverse pathological features. In addition, poor CSS and recurrence-free survival were associated with Ki-67 overexpression. However, the percentage of Ki-67 overexpression in urothelial carcinoma in their study was higher than previous research $(73.3 \%$ vs. $42.5-50 \%)[26,27]$. As a result, the interpretation of the outcomes might be affected by the high percentage of Ki-67 positivity in their study. There were $48 \%$ patients presenting Ki-67 overexpression in our study, and this was compatible with the percentage of $\mathrm{Ki}-67 \geq 20 \%$ in previous studies [26,27]. This might explain the different results between these studies. In another study, Krabbe et al. retrospectively examined 475 patients and reported that $\mathrm{Ki}-67$ overexpression was an independent predictor of the CSS and recurrence-free survival of patients with UTUC who underwent RNU [15]. Since there were discrepancies in the results in each model and a limitation of the retrospective analysis in most studies, this suggests that it is more reasonable to combine these known predictive markers from various pathways into a multivariable prognostic model than to only examine the single markers.

In our study, we found that Ki-67 overexpression was not associated with CSS and OS in the multivariable analysis. Although we enrolled Asian patients in our study, our results differed from those reported for Japanese and Korean patients. A cohort study examined and compared the pathological characteristics and behaviours of patients with UTUC between Taiwan and Japan [7]. The study reported that a higher proportion of Japanese patients exhibited lymphovascular invasion, whereas a higher proportion of Taiwanese patients demonstrated squamous differentiation. This unusual etiological difference between Japanese and Taiwanese patients can be because the Taiwanese patients with UTUC had different genetic susceptibilities or carcinogen exposure and tended to be non-smokers. The non-association of Ki-67 overexpression with CSS and OS observed in our study may partly be attributed to racial differences.

In this study, we investigated the Ki-67 overexpression and PD-L1 expression simultaneously. A shorter follow-up duration was found both in patients with PD-L1-positive expression and Ki-67 overexpression, which may be attributed to the poorer prognosis in these patients. Additionally, a CPS $\geq 10$ was associated with a higher pathological T stage. $\mathrm{Ki}-67$ overexpression was only associated with pathological T2 or higher. However, the linear-by-linear association test showed that Ki-67 overexpression was associated with a higher T stage $(p=0.030$,). Therefore, these results also implied that PD-L1 positivity may have a stronger association with a worse prognosis than $\mathrm{Ki}-67$ overexpression.

Few studies have examined the predictive value of Ki-67 expression in combination with PD-L1 positivity in patients with UTUC receiving RNU. To our knowledge, only one study, conducted by Rubino et al. in 2020, demonstrated that positive Ki-67 and PD-L1 expression in patients with muscle-invasive bladder cancer receiving neoadjuvant chemotherapy were associated with the OS [28]. They also found that the pathological $\mathrm{N}$ stage was associated with a poor OS [28]. To our knowledge, this is the first study to examine the prognostic value of Ki-67 overexpression and PD-L1 positivity at the same time in patients with UTUC receiving nephroureterectomy. No synergic effect was observed in the multivariable analysis when we combined Ki-67 overexpression and positive PD-L1 expression as a risk factor. PD-L1 positivity showed a stronger prognostic value than Ki-67 overexpression for CSS.

Our study was limited by its retrospective small-scale study and relatively shorter follow-up period (34.17 months). The prevalence of upper tract urothelial carcinoma is relatively low in comparison with bladder cancer. To minimise the specimen heterogeneity in this study, we only enrolled patients meeting the selection criteria, and this may have 
further minimised our sample size. Second, the lymph node status of most patients was determined on the basis of images. In addition, we did not routinely perform LND during RNU, because the benefits of LND are still under debate. We performed LND only if suspicious enlarged lymph nodes $(>10 \mathrm{~mm})$ were observed on the CT images before RNU or palpable enlarged lymph nodes were observed during the operation. Therefore, some nodal metastasis bias might have occurred. Third, given the relatively small sample size and few events, we failed to include all the established prognostic factors of OS or CSS in the multivariable analysis. However, we combined the prognostic variables with the most impact, such as immunochemical staining and the $\mathrm{T}$ and $\mathrm{N}$ stages, to evaluate the OS and CSS. Due to its higher prognostic value for CSS, PD-L1 may serve as a potential marker in treatment-related decision-making. The predictive value of PD-L1 should be examined in further prospective large-scale studies.

\section{Conclusions}

The results indicated that a positive PD-L1 expression with CPS $\geq 10$ was significantly associated with the pathological T stage. Additionally, a Ki-67 overexpression of $\geq 20 \%$ demonstrated a significant association with pathological $\mathrm{T} \geq 2$ and tumour necrosis. Compared with Ki-67 overexpression, positive PD-L1 expression was found to be a stronger independent prognostic factor for CSS in patients with UTUC.

Author Contributions: Conceptualisation, P.-H.C.; Methodology, P.-H.C.; Formal Analysis, M.-Y.T. and P.-C.C.; Investigation, M.-Y.T., P.-C.C., C.-H.C., M.-T.S. and S.-C.H.; Writing-Original Draft Preparation, M.-Y.T., C.-H.C., M.-T.S., S.-C.H. and P.-H.C.; and Writing-Review and Editing, M.-Y.T., C.-H.C., J.-L.S., E.-M.T. and P.-H.C. All authors have read and agreed to the published version of the manuscript.

Funding: This research received no external funding.

Institutional Review Board Statement: This study was conducted according to the guidelines of the Declaration of Helsinki and approved by the Institutional Review Board of Kaohsiung Chang Gung Memorial hospital (KCGMH) (protocol code: 202000185B0 and date of approval: 2020/02/12).

Informed Consent Statement: Patient consent was waived due to the retrospectively designed study.

Data Availability Statement: The data that support the findings of this study are available from the corresponding author upon reasonable request.

Acknowledgments: We appreciate the Biostatistics Center, Kaohsiung Chang Gung Memorial Hospital.

Conflicts of Interest: The authors declare no conflict of interest.

\section{References}

1. Yang, M.-H.; Chen, K.-K.; Yen, C.-C.; Wang, W.-S.; Chang, Y.-H.; Huang, W.J.-S.; Fan, F.S.; Chiou, T.-J.; Liu, J.-H.; Chen, P.-M. Unusually high incidence of upper urinary tract urothelial carcinoma in Taiwan. Urology 2002, 59, 681-687. [CrossRef]

2. Chen, J.-S.; Lu, C.-L.; Huang, L.-C.; Shen, C.-H.; Chen, S.C.-C. Chronic Kidney Disease is Associated with Upper Tract Urothelial Carcinoma: A Nationwide Population-Based Cohort Study in Taiwan. Medicine 2016, 95, e3255. [CrossRef]

3. Wu, T.T.; Chen, J.-H.; Lee, Y.-H.; Huang, J.-K. The role of bcl-2, p53, and ki-67 index in predicting tumor recurrence for low grade superficial transitional cell bladder carcinoma. J. Urol. 2000, 163, 758-760. [CrossRef]

4. Chen, C.-Y.; Liao, Y.-M.; Tsai, W.-M.; Kuo, H.-C. Upper Urinary Tract Urothelial Carcinoma in Eastern Taiwan: High Proportion Among All Urothelial Carcinomas and Correlation with Chronic Kidney Disease. J. Formos. Med. Assoc. 2007, 106, 992-998. [CrossRef]

5. Wang, S.-M.; Lai, M.-N.; Chen, P.-C.; Pu, Y.-S.; Lai, M.-K.; Hwang, J.-S.; Wang, J.-D. Increased upper and lower tract urothelial carcinoma in patients with end-stage renal disease: A nationwide cohort study in Taiwan during 1997-2008. Biomed Res. Int. 2014, 2014, 149750. [CrossRef]

6. Chen, C.-H.; Dickman, K.G.; Huang, C.-Y.; Moriya, M.; Shun, C.-T.; Tai, H.-C.; Huang, K.-H.; Wang, S.-M.; Lee, Y.-J.; Grollman, A.P.; et al. Aristolochic acid-induced upper tract urothelial carcinoma in Taiwan: Clinical characteristics and outcomes. Int. J. Cancer 2013, 133, 14-20. [CrossRef]

7. Luo, H.L.; Ohyama, C.; Hatakeyama, S.; Wang, H.J.; Yoneyama, T.; Yang, W.C.; Chuang, Y.C.; Chen, Y.T.; Lee, W.C.; Cheng, Y.T.; et al. Unusual presentation of upper urinary tract urothelial carcinoma in Taiwan: Direct comparison from Taiwan-Japan UTUC Collaboration Cohort. Int. J. Urol. 2020, 27, 327-332. [CrossRef] [PubMed] 
8. Wu, F.; Wang, T. Risk assessment of upper tract urothelial carcinoma related to aristolochic acid. Cancer Epidemiol. Biomark. Prev. 2013, 22, 812-820. [CrossRef] [PubMed]

9. Yang, H.-Y.; Wang, J.-D.; Lo, T.-C.; Chen, P.-C. Increased Risks of Upper Tract Urothelial Carcinoma in Male and Female Chinese Herbalists. J. Formos. Med. Assoc. 2011, 110, 161-168. [CrossRef]

10. Margulis, V.; Youssef, R.F.; Karakiewicz, P.I.; Lotan, Y.; Wood, C.G.; Zigeuner, R.; Kikuchi, E.; Weizer, A.; Raman, J.; Remzi, M.; et al. Preoperative multivariable prognostic model for prediction of nonorgan confined urothelial carcinoma of the upper urinary tract. J. Urol. 2010, 184, 453-458. [CrossRef]

11. Freifeld, Y.; Ghandour, R.; Singla, N.; Woldu, S.; Clinton, T.; Kulangara, R.; Bagrodia, A.; Matin, S.F.; Petros, F.G.; Raman, J.D.; et al. Preoperative predictive model and nomogram for disease recurrence following radical nephroureterectomy for high grade upper tract urothelial carcinoma. Urol. Oncol. 2019, 37, 758-764. [CrossRef]

12. Krabbe, L.-M.; Heitplatz, B.; Preuss, S.; Hutchinson, R.C.; Woldu, S.L.; Singla, N.; Boegemann, M.; Wood, C.G.; Karam, J.A.; Weizer, A.Z.; et al. Prognostic Value of PD-1 and PD-L1 Expression in Patients with High Grade Upper Tract Urothelial Carcinoma. J. Urol. 2017, 198, 1253-1262. [CrossRef]

13. Skala, S.L.; Liu, T.-Y.; Udager, A.M.; Weizer, A.Z.; Montgomery, J.S.; Palapattu, G.S.; Siddiqui, J.; Cao, X.; Fields, K.; Abugharib, A.E.; et al. Programmed Death-ligand 1 Expression in Upper Tract Urothelial Carcinoma. Eur. Urol. Focus 2017, 3, 502-509. [CrossRef]

14. Krabbe, L.-M.; Bagrodia, A.; Lotan, Y.; Gayed, B.A.; Darwish, O.M.; Youssef, R.F.; John, G.; Harrow, B.; Jacobs, C.; Gaitonde, M.; et al. Prospective analysis of Ki-67 as an independent predictor of oncologic outcomes in patients with high grade upper tract urothelial carcinoma. J. Urol. 2014, 191, 28-34. [CrossRef]

15. Krabbe, L.M.; Bagrodia, A.; Haddad, A.Q.; Kapur, P.; Khalil, D.; Hynan, L.S.; Wood, C.G.; Karam, J.A.; Weizer, A.Z.; Raman, J.D.; et al. Multi-institutional validation of the predictive value of Ki-67 in patients with high grade urothelial carcinoma of the upper urinary tract. J. Urol. 2015, 193, 1486-1493. [CrossRef]

16. Kamijima, S.; Tobe, T.; Suyama, T.; Ueda, T.; Igarashi, T.; Ichikawa, T.; Ito, H. The prognostic value of p53, Ki-67 and matrix metalloproteinases MMP-2 and MMP-9 in transitional cell carcinoma of the renal pelvis and ureter. Int. J. Urol. 2005, 12, 941-947. [CrossRef] [PubMed]

17. Jeon, H.G.; Jeong, I.G.; Bae, J.; Lee, J.W.; Won, J.-K.; Paik, J.H.; Kim, H.H.; Lee, S.E.; Lee, E. Expression of Ki-67 and COX-2 in patients with upper urinary tract urothelial carcinoma. Urology 2010, 76, 513.e7-513.e12. [CrossRef]

18. Wu, P.; Liu, S.; Zhang, W.; Zhang, Y.; Zhu, G.; Wei, D.; Wan, B.; Wang, J. Low-level Ki-67 expression as an independent predictor of bladder tumour recurrence in patients with primary upper tract urothelial carcinoma after radical nephroureterectomy. Jpn. J. Clin. Oncol. 2015, 45, 1175-1181. [CrossRef] [PubMed]

19. Mbeutcha, A.; Rouprêt, M.; Kamat, A.M.; Karakiewicz, P.I.; Lawrentschuk, N.; Novara, G.; Raman, J.D.; Seitz, C.; Xylinas, E.; Shariat, S.F. Prognostic factors and predictive tools for upper tract urothelial carcinoma: A systematic review. World J. Urol. 2017, 35, 337-353. [CrossRef]

20. Chen, C.-H.; Tsai, M.-Y.; Chiang, P.-C.; Sung, M.-T.; Luo, H.-L.; Suen, J.-L.; Tsai, E.-M.; Chiang, P.-H. Prognostic value of PD-L1 combined positive score in patients with upper tract urothelial carcinoma. Cancer Immunol. Immunother. 2021. [CrossRef] [PubMed]

21. Rouprêt, M.; Babjuk, M.; Burger, M.; Capoun, O.; Cohen, D.; Compérat, E.M.; Cowan, N.C.; Dominguez-Escrig, J.L.; Gontero, P.; Mostafid, A.H.; et al. European Association of Urology Guidelines on Upper Urinary Tract Urothelial Carcinoma: 2020 Update. Eur. Urol. 2021, 79, 62-79. [CrossRef] [PubMed]

22. Zhang, B.; Yu, W.; Feng, X.; Zhao, Z.; Fan, Y.; Meng, Y.; Hu, S.; Cui, Y.; He, Q.; Zhang, H.; et al. Prognostic significance of PD-L1 expression on tumor cells and tumor-infiltrating mononuclear cells in upper tract urothelial carcinoma. Med. Oncol. 2017, 34, 94. [CrossRef] [PubMed]

23. Miyama, Y.; Morikawa, T.; Miyakawa, J.; Koyama, Y.; Kawai, T.; Kume, H.; Fukayama, M. The prognostic value of PD-L1 expression in upper tract urothelial carcinoma varies according to platelet count. Cancer Med. 2018, 7, 4330-4338. [CrossRef] [PubMed]

24. Plimack, E.R.; Bellmunt, J.; Gupta, S.; Berger, R.; Chow, L.Q.M.; Juco, J.; Lunceford, J.; Saraf, S.; Perini, R.F.; O’Donnell, P.H. Safety and activity of pembrolizumab in patients with locally advanced or metastatic urothelial cancer (KEYNOTE-012): A non-randomised, open-label, phase 1b study. Lancet Oncol. 2017, 18, 212-220. [CrossRef]

25. Ding, X.; Chen, Q.; Yang, Z.; Li, J.; Zhan, H.; Lu, N.; Chen, M.; Yang, Y.; Wang, J.; Yang, D. Clinicopathological and prognostic value of PD-L1 in urothelial carcinoma: A meta-analysis. Cancer Manag. Res. 2019, 11, 4171-4184. [CrossRef]

26. Margulis, V.; Shariat, S.F.; Ashfaq, R.; Sagalowsky, A.I.; Lotan, Y. Ki-67 is an independent predictor of bladder cancer outcome in patients treated with radical cystectomy for organ-confined disease. Clin. Cancer Res. 2006, 12, 7369-7373. [CrossRef]

27. Margulis, V.; Lotan, Y.; Karakiewicz, P.I.; Fradet, Y.; Ashfaq, R.; Capitanio, U.; Montorsi, F.; Bastian, P.J.; Nielsen, M.E.; Müller, S.C.; et al. Multi-institutional validation of the predictive value of Ki-67 labeling index in patients with urinary bladder cancer. J. Natl. Cancer Inst. 2009, 101, 114-119. [CrossRef]

28. Rubino, S.; Kim, Y.; Zhou, J.; Dhilon, J.; Li, R.; Spiess, P.; Poch, M.; Manley, B.J.; Pow-Sang, J.; Gilbert, S.; et al. Positive Ki-67 and PD-L1 expression in post-neoadjuvant chemotherapy muscle-invasive bladder cancer is associated with shorter overall survival: A retrospective study. World J. Urol. 2021, 39, 1539-1547. [CrossRef] 